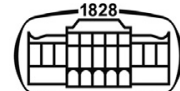

AKADÉMIAI KIADÓ

Journal of Behavioral Addictions

10 (2021) 3, 731-746

DOI:

$10.1556 / 2006.2021 .00052$

(c) 2021 The Author(s)

\section{FULL-LENGTH REPORT}

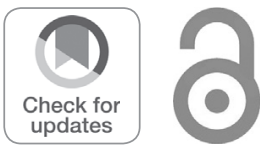

${ }^{\dagger} \mathrm{I}-\mathrm{H}$ Chen and C-Y Chen contributed equally as the first authors.

* Corresponding author. E-mail: cylin36933@gmail.com

\section{AKJournals}

\title{
Internet addiction and psychological distress among Chinese schoolchildren before and during the COVID-19 outbreak: A latent class analysis
}

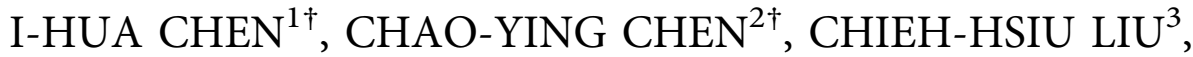 DANIEL KWASI AHORSU ${ }^{4}$, MARK D. GRIFFITHS $^{5}$,

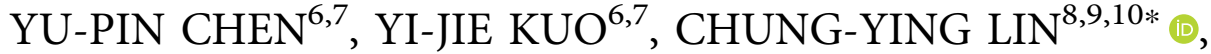 AMIR H. PAKPOUR ${ }^{1,12}$ and SHU-MEI WANG ${ }^{4}$}

${ }^{1}$ Chinese Academy of Education Big Data, Qufu Normal University, Qufu, China

${ }^{2}$ School of Physical Therapy and Graduate Institute of Rehabilitation Science, College of Medicine, Chang Gung University, Taoyuan, Taiwan

${ }^{3}$ Department of Geriatrics and Gerontology, Research Center of Clinical Medicine, National Cheng Kung University Hospital, Tainan, Taiwan

${ }^{4}$ Department of Rehabilitation Sciences, Faculty of Health and Social Sciences, The Hong Kong Polytechnic University, Hung Hom, Hong Kong

${ }^{5}$ International Gaming Research Unit, Psychology Department, Nottingham Trent University, Nottingham, UK

${ }^{6}$ Department of Orthopedic Surgery, Wan Fang Hospital, Taipei Medical University, Taipei, Taiwan

${ }^{7}$ Department of Orthopedic Surgery, School of Medicine, College of Medicine, Taipei Medical University, Taipei, Taiwan

${ }^{8}$ Institute of Allied Health Sciences, College of Medicine, National Cheng Kung University, Tainan, Taiwan

${ }^{9}$ Department of Occupational Therapy, College of Medicine, National Cheng Kung University, Tainan, Taiwan

${ }^{10}$ Department of Public Health, National Cheng Kung University Hospital, College of Medicine, National Cheng Kung University, Tainan, Taiwan

${ }^{11}$ Social Determinants of Health Research Center, Research Institute for Prevention of NonCommunicable Diseases, Qazvin University of Medical Sciences, Qazvin 3419759811, Iran

${ }^{12}$ Department of Nursing, School of Health and Welfare, Jönköping University, Jönköping, Sweden

Received: October 29, 2020 • Revised manuscript received: April 28, 2021; July 10, 2021 • Accepted: July 10, 2021 Published online: September 15, 2021

\section{ABSTRACT}

Background and aims: The present longitudinal study examined the changes in problematic internet use (problematic smartphone use, problematic social media use, and problematic gaming) and changes in COVID-19-related psychological distress (fear of COVID-19 and worry concerning COVID-19) across three time-points (before the COVID-19 outbreak, during the initial stages of the COVID-19 outbreak, and during the COVID-19 outbreak recovery period). Methods: A total of 504 Chinese schoolchildren completed measures concerning problematic internet use and psychological distress across three timepoints. Latent class analysis (LCA) was used to classify participants into three groups of problematic internet use comprising Group 1 (lowest level), Group 2 (moderate level), and Group 3 (highest level). Results: Statistical analyses showed that as problematic use of internet-related activities declined among Group 3 participants across the three time points, participants in Group 1 and Group 2 had increased problematic use of internet-related activities. Although there was no between-group difference in relation to worrying concerning COVID-19 infection, Groups 2 and 3 had significantly higher levels of fear of COVID-19 than Group 1 during the COVID-19 recovery period. Regression analysis showed that change in problematic internet use predicted fear of COVID-19 during the recovery period. 
Conclusion: The varied levels of problematic internet use among schoolchildren reflect different changing trends of additive behaviors during COVID-19 outbreak and recovery periods.

\section{KEYWORDS}

COVID-19, problematic gaming, problematic social media use, problematic smartphone use, psychological distress

\section{INTRODUCTION}

The coronavirus disease 2019 (COVID-19) is an infectious respiratory disease that has affected physical, mental, and social well-being among individuals worldwide on an unprecedented scale (Ahorsu, Imani, et al., 2020; Ahorsu, Lin, \& Pakpour, 2020; Fazeli et al., 2020; Lin \& Cheng, 2020). In mainland China, governments imposed a lockdown on severely affected cities, such as Wuhan, in early 2020 to prevent the further spread of COVID-19. In addition, all schools in China were shut down during the initial COVID19 outbreak in order to reduce social contact and prevent large-scale groups gathering. Schoolchildren were asked to stay home, keep socially isolated, and to use the internet to engage in everyday activities. More specifically, in order to control the spread of COVID-19, schoolchildren were encouraged by governmental authorities to stay home and use the internet to engage in everyday activities including teaching/learning, socializing, and leisure activities. Therefore, schoolchildren were more likely to be exposed to online activities during the initial COVID-19 outbreak than previously.

Such prolonged exposure to the internet may increase risks of developing problematic internet use (e.g., problematic smartphone use [PSU], problematic social media use [PSMU], and problematic gaming [PG]). Recent studies (e.g., Siste et al., 2020; Sun et al., 2020) have reported an increase in the prevalence of severe internet dependence among the general public from before the COVID-19 outbreak to during the COVID-19 outbreak. However, to date, there has been little investigation concerning changes in the problematic internet use in schoolchildren across three stages of the COVID-19 pandemic: before the COVID19 outbreak, during the initial stages of the COVID-19 outbreak, and during the COVID-19 outbreak recovery period.

During the COVID-19 outbreak, schoolchildren were overwhelmed by the large amount of online news and information concerning the disease (Cachón-Zagalaz et al., 2020). Problematic internet use may further intensify their emotions of fear and worry concerning the disease (i.e., causing psychological distress). Overloading schoolchildren with information such as the disease uncertainty, the sudden surge in infected individuals, invisible transmission of the disease, and the relatively high mortality rate can cause some schoolchildren to worry about the virus and increase fears about being infected (Ahorsu, Lin, et al., 2020; Asmundson
\& Taylor, 2020). In research regarding COVID-19, worry and fear of the disease have been viewed as types of major psychological distress experienced by the general public during the pandemic (e.g., Di Blasi et al., 2021; Satici, GocetTekin, Deniz, \& Satici, 2020). Moreover, it has been shown that fear of COVID-19 is a risk factor of depression and anxiety among individuals (Satici et al., 2020). Therefore, fear and worry can be interpreted as being both the early signs of psychological distress, as well as being viewed as types of psychological distress in themselves. The present study therefore included an assessment of fear and worry concerning COVID-19 when investigating psychological distress in participants.

Moreover, research by Dong, Yang, Lu, and Hao (2020) indicated that problematic internet use during the COVID19 pandemic is associated with anxiety and depression among children and adolescents. However, their study did not investigate psychological distress specifically related to COVID-19 (i.e., fear and worry about COVID-19). Furthermore, fear and worry concerning the disease may still exist even during the more recent COVID-19 recovery stage. Therefore, it is unclear whether psychological distress (i.e., fear and worry concerning COVID-19) during the COVID-19 recovery stage differs among schoolchildren with different levels of problematic internet use. Consequently, the present longitudinal study investigated the impacts of the pandemic on problematic internet use and psychological distress during COVID-19 pandemic, and associations between these two variables among schoolchildren during three different COVID-19 stages (before the COVID-19 outbreak, during the initial stages of the COVID-19 outbreak, and during the COVID-19 outbreak recovery period).

Although there is no consensus concerning the taxonomy of problematic internet use (or other related terms such as internet addiction and internet use disorder), problematic internet use has been defined as excessive preoccupation to use the internet to the extent that it causes clinical impairments in various life domains such as the compromising of relationships, occupation and/or education (Montag, Wegmann, Sariyska, Demetrovics, \& Brand, 2020; Shaw \& Black, 2008; Weinstein, Feder, Rosenberg, \& Dannon, 2014). Because the levels of problematic internet use can be reflected by various online activities via many devices including computers, laptops, tablets, and smartphones (i.e., PSU, PSMU, and PG are all included in the umbrella term 'problematic internet use'), different types of problematic internet use (i.e., PSU, PSMU, and PG) should be simultaneously considered when determining the level of problematic internet use for a schoolchild. According to the components model of addiction (Griffiths, 2005), all types of problematic internet use comprise distinct common components. Shaw and Black (2008) further indicated that internet addiction (the most extreme form of problematic internet use on the continuum) is characterized by impairment and/or distress caused by excessive use and/or poorly controlled online activity use. Consequently, scholars working in the field of problematic internet use include 
behaviors such as PSU, PSMU, and PG being under the umbrella term 'problematic internet use'. Therefore, latent class analysis (Jeon, Lee, Anthony, \& Chung, 2017) is an appropriate method that can be utilized to classify schoolchildren into different levels of problematic internet use via measures assessing PSU, PSMU, and PG. More specifically, latent class analysis can use information regarding PSU, PSMU, and PG to propose the best classifying groups that reflect different levels of problematic internet use.

Although problematic internet use may cause health problems (Shaw \& Black, 2008), Kardefelt-Winther (2014) proposed a model of compensatory internet use and advocated (like other scholars in the field previously) that internet use is on a continuum from non-problematic at one end to problematic at the other. The positive benefits of internet use far outweigh the negatives. For instance, RuizAriza, Casuso, Suarez-Manzano, and Martínez-López (2018) reported that playing the Pokémon Go videogame can improve social relationships, physical activity, and cognitive performance among schoolchildren. Hurwitz and Schmitt (2020) reported that the acquisition of digital skills via internet use is beneficial for schoolchildren's future school performance. However, due to the impact of the COVID-19 pandemic, schoolchildren are likely to have increased their internet use and for a minority will result in problematic internet use (Chen, Chen, Pakpour, Lin, \& Griffiths, 2021). Prior evidence has shown positive significant relationships between problematic internet use and psychological distress in both cross-sectional and longitudinal studies. More specifically, greater problematic internet use is associated with increased concurrent psychological distress (Chang, Chang, Hou, Lin, \& Griffiths, 2020) or in the future (Chen, Chen, Hou, et al., 2021; Chen, Pakpour et al., 2020). Further investigations are therefore needed to examine the relationship between problematic internet use and psychological distress across different stages of COVID-19 pandemic. More specifically, classifying schoolchildren into different levels of problematic internet use may provide further information for healthcare providers to understand the associations between problematic internet use and psychological distress across different periods of COVID-19 outbreak.

The present longitudinal study investigated the changes in problematic internet use (comprising PSU, PSMU, and PG) and changes in COVID-19-related psychological distress (including fear of COVID-19 and worry concerning COVID-19) across the three aforementioned stages among schoolchildren. It also examined the associations between changes in problematic internet use across the three pandemic stages and COVID-19-related psychological distress during the COVID-19 recovery stage among schoolchildren. According to prior evidence regarding positive associations between problematic internet use and psychological distress (Chang, Chang, et al., 2020; Chen, Chen, Hou, et al., 2021; Chen, Pakpour et al., 2020), the present study hypothesized that (i) the group with higher level of problematic internet use would have greater psychological distress across different stages of COVID-19 pandemic; and (ii) changes of problematic internet use would be associated with COVID-19-related psychological distress. Aside from the hypotheses, the present study explored the trajectory of PSU, PSMU, and PG across three stages of COVID-19 outbreak (i.e., before the COVID-19 outbreak, during the outbreak, and during recovery) given that there is no relevant evidence currently.

\section{METHODS}

\section{Data collection procedure and participants}

Using three waves of data from an ongoing longitudinal project (before the COVID-19 outbreak [Time 1; collected in mid-January, 2020], during the initial stages of the COVID19 outbreak [Time 2; collected in mid-March, 2020], and during the COVID-19 outbreak recovery period [Time 3; collected in early June, 2020]), the study examined how the COVID-19 pandemic impacted schoolchildren's problematic internet use and their psychological distress (i.e., fear and worry concerning COVID-19 infection) during the COVID-19 pandemic. More specifically, the associations between the problematic use of internet-related activities and COVID-19-related psychological distress (including worry concerning COVID-19 infection assessed at Time 2 and Time 3; fear of COVID-19 assessed at Time 3) were assessed.

Through collaborations with three primary schools, which were all public schools located in the suburban area of a country-level city in the Sichuan province (i.e., Qionglai city), a convenience sampling method was used for the present longitudinal study. The teachers of the three schools assisted in inviting eligible schoolchildren from the selected classes to participate in the study. Most parents of the schoolchildren in the three schools had completed high school education (85\%) or had a college degree (5\%). On average, the parents of the entire schoolchildren in the three schools had annual income at 80,000 Renminbi $(\mathrm{RMB} ; 1 \mathrm{USD} \approx 7.05 \mathrm{RMB})$ ranging between 50,000 and $180,000 \mathrm{RMB}$. At the beginning of the study, the teachers approached 550 eligible schoolchildren and parents and 543 agreed to participate in the initial survey (Time 1). All the schoolchildren were approached again for the follow-up surveys (Time 2 and Time 3). A total of 504 completed all three surveys (retention rate at $91.6 \%$ ).

Time 1 data (a total of 26 items) were collected using a paper-based survey. Here, teachers of the three primary schools in Sichuan province distributed paper-based surveys to the participants to complete. Data at Time 2 (a total of 27 items) and Time 3 (a total of 34 items) were collected using an online survey. Here, the research team sent the online survey to the teachers who then sent the survey hyperlink to the parents of the schoolchildren who participated in the survey at Time 1 . The data in Time 1 were collected before the Chinese New Year (i.e., mid-January, 2020), when several COVID-19 infected cases had been confirmed in Wuhan but the world and mainland China did not treat it as a global threat (i.e., before the COVID-19 pandemic). Time 
2 data were collected just after the World Health Organization declared COVID-19 to be a pandemic (i.e., midMarch 2020). During Time 2, the children in Sichuan province received online learning as they were housebound and were prohibited to go to their school campus. Time 3 data were collected in the period that the students in Sichuan province were allowed to go back to their school campus to receive face-to-face teaching. Moreover, the confirmed cases of COVID-19 were low in mainland China during the Time 3 data collection. Therefore, Time 1 data were representative for the period before the COVID-19 outbreak; Time 2 data were representative for the period during the initial COVID19 outbreak; and Time 3 data were representative for the period during the COVID-19 outbreak recovery stage.

The following inclusion criteria were used to define the eligibility of the participants: (i) schoolchildren studying in a primary school; (ii) schoolchildren with sufficient literacy skills (as verified by experienced schoolteachers) who could understand the meaning of the survey questions without difficulty; and (iii) schoolchildren with parents who had a smartphone that could access the internet during the study period.

\section{Measures}

On average, the schoolchildren completed the surveys in $14.59 \mathrm{~min}$ ( $\mathrm{SD}=20.09$; range between 10 and $45 \mathrm{~min}$ ). All participants completed the measures in the same sequence without any counterbalancing. There were no incentives for the participants to complete the surveys.

Problematic smartphone use (PSU). The Smartphone Application-Based Addiction Scale (SABAS; Csibi, Demetrovics, \& Szabo, 2016) with six items was used to assess PSU among the schoolchildren. Guided by the addiction components model, the SABAS was developed using six criteria (i.e., salience, mood modification, tolerance, withdrawal conflict and relapse) as proposed by Griffiths (2000, 2005). The six SABAS items are rated using a six-point Likert-type scale and all the items are worded in the same direction. The higher the SABAS score, the higher the level of PSU. The SABAS has been translated into different language versions including Chinese (Chen, Ahorsu, et al., 2020; Yam et al., 2019). All previously translated versions of the SABAS demonstrated strong psychometric properties (e.g., Altundağ, Yandi, \& Ünal, 2019; Chen, Ahorsu, et al., 2020; Csibi, Griffiths, Cook, Demetrovics, \& Szabo, 2018; Gökler \& Bulut, 2019; Lin, Imani et al., 2019; Sojević, Pećanac, \& Latas, 2018; Soraci, Ferrari, Urso, \& Griffiths, 2020; Yam et al., 2019) and are comparable to the original SABAS (Csibi et al., 2016). Moreover, the SABAS was recently validated for use among schoolchildren (Chen, Ahorsu, et al., 2020). The SABAS was assessed throughout the three-wave survey and the Chinese SABAS used in the present study also showed very good internal consistency ( $\alpha=0.85-0.90$ across the three time points).

Problematic social media use (PSMU). The Bergen Social Media Addiction Scale (BSMAS; Andreassen et al., 2016) with six items was used to assess PSMU among the schoolchildren. The BSMAS was developed based on the aforementioned addiction components model. The six BSMAS items are rated using a five-point Likert-type scale and all the items are worded in the same direction. The higher the BSMAS score, the higher the level of PSMU. The BSMAS has been translated into different language versions including Chinese (Chen, Ahorsu, et al., 2020; Yam et al., 2019). All the previously translated versions of BSMAS demonstrated strong psychometric properties (e.g., Bányai et al., 2017; Chen, Ahorsu, et al., 2020; Chen, Strong, et al., 2020; Leung et al., 2020; Lin, Broström, Nilsen, Griffiths, \& Pakpour, 2017; Monacis, de Palo, Griffiths, \& Sinatra, 2017; Yam et al., 2019) and are comparable to the original BSMAS (Andreassen et al., 2016). Moreover, the BSMAS was recently validated for use among schoolchildren (Chen, Ahorsu, et al., 2020). The BSMAS was assessed throughout the three-wave survey and the Chinese BSMAS used in the present study also showed very good internal consistency ( $\alpha=0.79-0.90$ across three time points).

Problematic gaming (PG). The Internet Gaming Disorder Scale-Short Form (IGDS9-SF; Pontes \& Griffiths, 2015) with nine items was used to assess PG among the schoolchildren. Guided by the DSM-5 (American Psychiatric Association, 2013), the IGDS9-SF was developed using DSM5 's internet gaming disorder [IGD] criteria. The nine IGDS9-SF items are rated using a five-point Likert-type scale and all the items are worded in the same direction. The higher the IGDS9-SF score, the higher the level of PG. The IGDS9-SF has been translated into different language versions including Chinese (Chen, Ahorsu, et al., 2020; Yam et al., 2019). All the previously translated versions of IGDS9SF demonstrated strong psychometric properties (e.g., Arıcak, Dinç, Yay, \& Griffiths, 2019; Beranuy et al., 2020; Monacis, de Palo, Griffiths, \& Sinatra, 2016; Pontes, Macur, \& Griffiths, 2016; Pontes, Stavropoulos, \& Griffiths, 2017; T'ng \& Pau, 2020; Wu et al., 2017; Yam et al., 2019) and are comparable to the original IGDS9-SF (Pontes \& Griffiths, 2015). Moreover, the IGDS9-SF was recently validated for use among schoolchildren (Chen, Ahorsu, et al., 2020). The IGDS9-SF was assessed throughout the three-wave survey and the Chinese IGDS9-SF used in the present study also showed very good internal consistency $(\alpha=0.87-0.93$ across the three time points).

Worry concerning COVID-19 infection. The 0-10 Visual Analogue Scale (VAS) was used to assess the worry concerning COVID-19 infection among the schoolchildren. Although there are criticisms regarding the use of a single item instead of using multiple items to capture an underlying concept (Fisher, Matthews, \& Gibbons, 2016), the use of the single VAS item to assess the worry was recently validated in prior research on schoolchildren (Chen, Chen, Hou, et al., 2021). More specifically, the general consensus is that using multiple items to assess an underlying concept can have better psychometric properties than using a single item. However, single-item measure is useful if its 
psychometric properties (i.e., concurrent validity that tests the correlation between the single-item measure with another multiple-item measure on the same construct) have been confirmed. The higher the score of the VAS, the higher the level of worry concerning COVID-19 infection. This item was assessed only in the survey at Time 2 and Time 3.

Fear of COVID-19. The seven-item Fear of COVID-19 Scale (FCV-19S; Ahorsu, Lin, et al., 2020) was used to assess fear of COVID-19 among the schoolchildren. Guided by Protection Motivation Theory (Pakpour, Griffiths, Chang, et al., 2020; Rogers, 1975), the FCV-19S was developed using the components stated in the theory. The FCV-19S items are rated using a five-point Likert-type scale and all the items are worded in the same direction. The higher the FCV-19S score, the higher the level of fear of COVID-19. The FCV$19 \mathrm{~S}$ has been translated into different language versions including Chinese (Chang, Hou, Pakpour, Lin, \& Griffiths, 2020). All the previously translated versions of FCV-19S demonstrate strong psychometric properties (e.g., Alyami, Henning, Krägeloh, \& Alyami, 2020; Bitan et al., 2020; Chang, Hou, et al., 2020; Pakpour, Griffiths, \& Lin, 2020; Pang et al., 2020; Sakib et al., 2020; Satici et al., 2020; Soraci, Ferrari, Abbiati, et al., 2020; Tsipropoulou et al., 2020) and are comparable to the original FCV-19S (Ahorsu, Lin, et al., 2020). Moreover, the FCV-19S was recently validated for use among schoolchildren (Lin et al., 2021). The FCV-19S was only assessed in the survey at Time 3 and the Chinese FCV$19 \mathrm{~S}$ used in the present study showed excellent internal consistency $(\alpha=0.92)$.

\section{Data analysis}

Latent class analysis (LCA) was conducted to classify the participants into different groups based on their problematic use of internet-related activities. More specifically, the total scores on the SABAS, BSMAS, and IGDS9-SF collected before COVID-19 outbreak (i.e., Time 1) were used in the LCA to classify the participants into groups. Entropy, the Lo-Mendell-Rubin (LMR) test, the bootstrapped (BLRT) likelihood ratio test, Bayesian information criterion (BIC), and sample-size-adjusted BIC (SABIC) were used to determine how many groups should be classified. Higher entropy and lower BIC with SABIC were used to determine the number of groups. Moreover, the LMR and BLRT tests were used to examine whether the different solutions in the number of classes were significantly different. After using LCA to determine the number of groups, the participants were classified into a group according to their performance of SABAS, BSMAS, and IGDS9-SF in Time 1. Then, the R3Step method was applied to examine whether the classified groups are different in the performance of SABAS, BSMAS, and IGDS9-SF.

Descriptive statistics including means and frequencies were used to understand the participants' characteristics for the entire sample and the LCA-determined groups. Following this, several statistical analyses were adopted to answer the hypotheses in the present study. For testing the first hypothesis (i.e., whether the group with higher level of problematic internet use had greater psychological distress across different stages of COVID-19 pandemic), a repeated measures analysis of variance (ANOVA) was employed. The ANOVA included COVID-19-related psychological distress assessed at both Time 2 and Time 3 as the dependent variable, Group (the LCA-determined groups), Time (Time 2 and Time 3), and their interaction (i.e., interaction between LCAdetermined groups and time) as the independent variables. Bonferroni post-hoc tests were employed to further examine significant effects (using a $P<0.05$ criterion for significance) when significant main effects or interaction effects existed.

For testing the second hypothesis (i.e., whether changes in problematic internet use would be associated with COVID19-related psychological distress), three mixed-effect models using difference scores (i.e., Time 2 score minus Time 1 score and Time 3 score minus Time 2 score) of problematic internet use (i.e., SABAS, BSMAS, and IGDS9-SF) as the dependent variables; Time (i.e., Time 2 and Time 3), COVID19-related psychological distress (assessed at Time 2 and Time 3) and their interaction as the independent variables; and individuals as a random factor. Post-hoc tests and slope analyses were employed to further examine significant slopes.

For exploring trajectories of PSU, PSMU, and PG across three stages of the COVID-19 outbreak (i.e., before the COVID-19 outbreak, during the outbreak, and during recovery), growth mixture models were employed on the SABAS, BSMAS, and IGDS9-SF scores assessed at the three time points. In the growth mixture models, diagonally weighted least squares estimator was used and several fit indices were used to evaluate whether the models are supported. More specifically, Tucker-Lewis index (TLI) and comparative fit index (CFI) $>0.9$ together with root mean square error of approximation (RMSEA) and standardized root mean square residual $($ SRMR $)<0.08$ indicate a supported growth mixture model. Moreover, when a nonnormal distribution was found in the variables of the applied statistical analyses, non-parametric methods were employed (e.g., using Friedman's ANOVA to replace the ANOVA).

\section{Ethics}

The study protocol was approved by the research team's universities. Additionally, all the participants and one of their parents provided their written assent and informed consent. All participants were assured of confidentiality anonymity, and freedom of withdraw their data at any time.

\section{RESULTS}

Based on the LCA results, the participants were categorized into three groups. More specifically, the entropy of the three-group solution was good (0.74) as compared to using the solutions equal to or more than four groups (0.42-0.62). Moreover, the BIC and SABIC of the three-group solution $(2,175.53$ and $2,140.61)$ were the lowest among all the other solutions (2,182.64-2,219.90 for BIC and 2,144.56 to $2,188.16$ for SABIC). In addition, the patterns of the three 
groups in the Time 1 scores on the SABAS, BSMAS, and IGDS9-SF were distinct (Fig. 1): Group 1 had the lowest scores on the SABAS, BSMAS, and IGDS9-SF instruments; Group 3 had the highest scores on all three instruments; and Group 2 had all their three instruments' scores between Group 1's and Group 3's scores. Therefore, Group 1 was defined as the lowest level problematic internet use group $(n=195)$; Group 2 was defined as the moderate level problematic internet use group $(n=268)$; and Group 3 was defined as the high problematic internet use group $(n=41)$. Both LMR and BLRT tests supported the use of three-group solution as this solution was significantly better than the other solutions (Fig. 1). Moreover, the R3Step method indicated that the three groups were significantly different in the performance of SABAS, BSMAS, and IGDS9-SF (Wald statistics $=740.57-34,494.44 ; P<0.001)$.

Table 1 further illustrates the participants' characteristics of the entire group ( $N=504 ; 252$ boys; mean age $=11.29$ years $[\mathrm{SD}=0.82]$ ), and Groups 1 to 3 . In general, the age, sex distribution, ethnicity distribution, and health status (i.e., whether currently sick or not) were similar among the three groups with different levels of problematic use of

\begin{tabular}{|c|c|c|c|c|c|c|c|c|}
\hline Model & $L^{2}$ & npar & $\mathrm{df}$ & BIC & SABIC & Entropy & $\begin{array}{l}\text { LMR } \\
\text { (p-value) }\end{array}$ & $\begin{array}{l}p \text {-value of } \\
\text { BLRT test }\end{array}$ \\
\hline 1-DFctor (2) & -1078.84 & 10 & 16 & 2219.90 & 2188.16 & 0.77 & -- & -- \\
\hline 1-DFetor (3) & -1053.54 & 11 & 15 & 2175.53 & 2140.61 & 0.74 & $50.59(<0.01)$ & $<0.01$ \\
\hline 1-DFctor (4) & -1053.99 & 12 & 14 & 2182.64 & 2144.56 & 0.62 & $-0.89(0.97)$ & 0.82 \\
\hline 1-DFctor (5) & -1053.66 & 13 & 13 & 2188.21 & 2146.95 & 0.59 & $0.65(0.21)$ & 0.56 \\
\hline 1-DFctor (6) & -1053.86 & 14 & 12 & 2194.83 & 2150.40 & 0.48 & $-0.40(0.96)$ & 0.83 \\
\hline 1-DFctor (7) & -1053.71 & 15 & 11 & 2200.76 & 2153.15 & 0.50 & $0.29(0.08)$ & 0.29 \\
\hline 1-DFctor (8) & -1053.83 & 16 & 10 & 2207.21 & 2156.43 & 0.42 & $-0.23(0.93)$ & 0.83 \\
\hline 1-DFctor (9) & -1053.75 & 17 & 9 & 2213.27 & 2159.31 & 0.44 & $0.16(0.14)$ & 0.32 \\
\hline
\end{tabular}

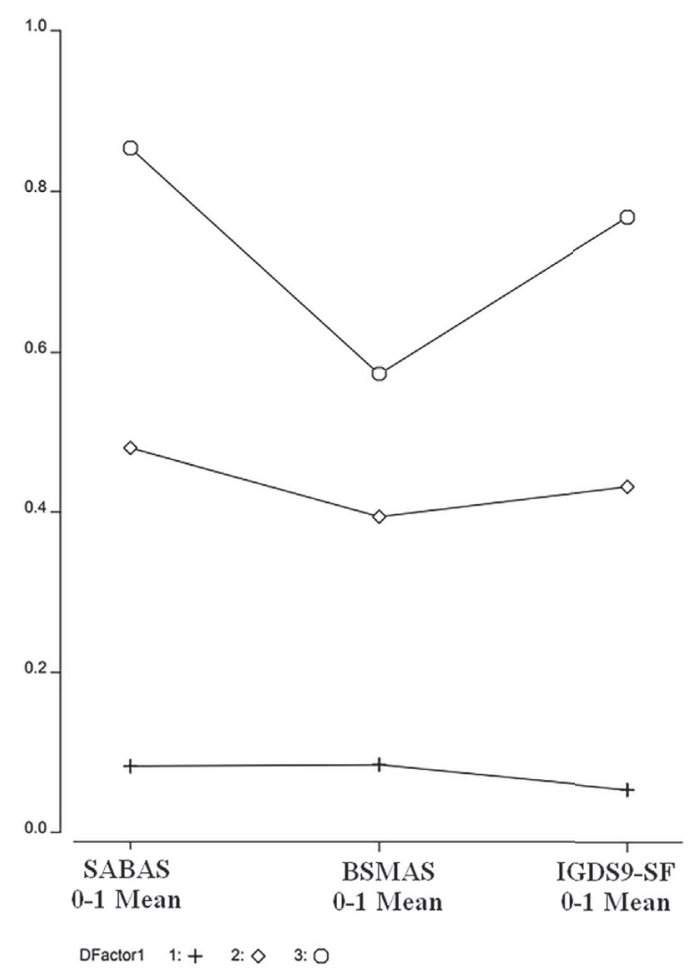

Group $1(+)$ : Having the lowest level of problematic internet use; Group $2(\diamond)$ : Having the middle level of problematic internet use; Group 3 (०): Having the highest level of problematic internet use.

SABAS=Smartphone Application Based Addiction Scale; BSMAS=Bergen Social Media Addiction Scale; IGDS9-SF=Nine-item Internet Gaming Disorder Scale-Short Form; FCV19S=Fear of COVID-19 Scale.

Fig. 1. Latent class analysis (with the most satisfactory model fit is in bold) 
Table 1. Participants' socio-demographic characteristics

\begin{tabular}{|c|c|c|c|c|}
\hline & Entire group $(N=504)$ & Group $1(N=195)$ & Group $2(N=268)$ & Group $3(N=41)$ \\
\hline Age in years; $M(S D)$ & $11.29(0.82)$ & $11.18(0.73)$ & $11.36(0.85)$ & $11.37(0.97)$ \\
\hline \multicolumn{5}{|l|}{ Grade; $n(\%)$} \\
\hline First & $3(0.6)$ & $1(0.51)$ & $1(0.37)$ & $1(2.44)$ \\
\hline Second & $2(0.4)$ & $2(1.03)$ & 0 & 0 \\
\hline Third & $2(0.4)$ & $1(0.51)$ & $1(0.37)$ & 0 \\
\hline Fourth & $140(27.8)$ & $64(32.82)$ & $66(24.63)$ & $10(24.39)$ \\
\hline Fifth & $296(58.7)$ & $117(60.00)$ & $160(59.70)$ & $19(46.34)$ \\
\hline Sixth & $61(12.1)$ & $10(5.13)$ & $40(14.93)$ & $11(26.83)$ \\
\hline \multicolumn{5}{|l|}{ Ethnicity; $n$ (\%) } \\
\hline Han & $493(97.8)$ & $191(97.95)$ & $262(97.76)$ & $40(97.56)$ \\
\hline Others & $11(2.2)$ & $4(2.05)$ & $6(2.24)$ & $3(2.44)$ \\
\hline \multicolumn{5}{|l|}{ Sex; $n(\%)$} \\
\hline Boys & $252(50)$ & $74(37.95)$ & $151(56.34)$ & $27(65.85)$ \\
\hline Girls & $252(50)$ & $121(62.05)$ & $117(43.66)$ & $14(34.15)$ \\
\hline \multicolumn{5}{|l|}{ Current sickness; $n(\%)$} \\
\hline Yes & $27(5.4)$ & $8(4.10)$ & $18(6.72)$ & $1(2.44)$ \\
\hline No & $477(94.6)$ & $187(95.90)$ & $250(93.28)$ & $40(97.56)$ \\
\hline
\end{tabular}

Note. Han is the dominant ethnic group in China. Current sickness refers to acute illnesses such as having colds and that do not include COVID-19.

internet-related activities. However, Group 3, comprised more sixth graders than Groups 1 and 2.

The problematic use of internet-related activities and psychological distress across different assessment periods (i.e., Time 1 to Time 3 ) were all close to normal distribution (skewness $=0.25-2.72 ;$ kurtosis $=-1.09-10.30)$. Moreover, COVID-19-related psychological distress and the problematic use of internet-related activities and the measures across three timepoints had significant interaction effects (Table 2). Based on the significant main effects (Table 2),

Table 2. Results of analysis of variance in three groups across three time points

\begin{tabular}{|c|c|c|c|c|c|c|}
\hline & SS & $d f$ & $M S$ & $F$ & $p$ & $\eta_{\mathrm{p}}{ }^{2}$ \\
\hline \multicolumn{7}{|l|}{ Worry } \\
\hline Group & 159.88 & 2 & 79.94 & 5.62 & 0.004 & 0.023 \\
\hline residuals (between group) & $6,829.99$ & 480 & 14.23 & & & \\
\hline Time point & 122.93 & 1 & 122.93 & 13.69 & $<0.001$ & 0.028 \\
\hline Group ${ }^{\star}$ Timepoint & 13.38 & 2 & 6.69 & 0.75 & 0.475 & 0.003 \\
\hline residuals (within group) & $4,308.90$ & 480 & 8.98 & & & \\
\hline \multicolumn{7}{|l|}{ SABAS } \\
\hline Group & 277.50 & 2 & 138.75 & 138.76 & $<0.001$ & 0.356 \\
\hline residuals (between group) & 500.948 & 501 & 1.00 & & & \\
\hline Time point & 18.25 & 2 & 9.125 & 21.63 & $<0.001$ & 0.041 \\
\hline Group ${ }^{\star}$ Timepoint & 69.20 & 4 & 17.30 & 41.00 & $<0.001$ & 0.141 \\
\hline residuals (within group) & 422.81 & 1,002 & 0.42 & & & \\
\hline \multicolumn{7}{|l|}{ BSMAS } \\
\hline Group & 65.28 & 2 & 32.64 & 74.25 & $<0.001$ & 0.229 \\
\hline residuals (between group) & 220.25 & 501 & 0.44 & & & \\
\hline Time point & 8.00 & 2 & 4.00 & 18.12 & $<0.001$ & 0.035 \\
\hline Group ${ }^{\star}$ Timepoint & 13.23 & 4 & 3.31 & 14.97 & $<0.001$ & 0.056 \\
\hline residuals (within group) & 221.36 & 1,002 & 0.22 & & & \\
\hline \multicolumn{7}{|l|}{ IGDS9-SF } \\
\hline Group & 85.14 & 2 & 42.57 & 145.27 & $<0.001$ & 0.367 \\
\hline residuals (between group) & 146.82 & 501 & 0.29 & & & \\
\hline Time point & 13.30 & 2 & 6.67 & 41.32 & $<0.001$ & 0.076 \\
\hline Group ${ }^{*}$ Timepoint & 23.71 & 4 & 5.93 & 36.75 & $<0.001$ & 0.128 \\
\hline residuals (within group) & 161.63 & 1,002 & 0.16 & & & \\
\hline
\end{tabular}

SABAS = Smartphone Application Based Addiction Scale; BSMAS = Bergen Social Media Addiction Scale; IGDS9-SF = Internet Gaming Disorder Scale-Short Form; Worry = Worry concerning COVID-19 infection.

SS $=$ sum of square; $d f=$ degree of freedom; MS = mean square.

Group 1 = Having the lowest level of problematic internet use; Group 2 = Having the middle level of problematic internet use; Group $3=$ Having the highest level of problematic internet use. 
Bonferroni post-hoc tests were conducted. The post-hoc tests showed that Group 2 had significantly higher worry concerning COVID-19 infection than Group 1 irrespective of the time points (i.e., during the COVID-19 outbreak or recovery periods). Moreover, Groups 2 and 3 had significantly higher levels of fear of COVID-19 than Group 1 during the COVID-19 recovery period (Table 3 ). In relation to worry concerning COVID-19 infection, Groups 1 and 2 had significantly higher level of worry during the COVID-19 outbreak period than during COVID-19 recovery period (Table 3). Regarding problematic internet use, Group 3 maintained the highest level of problematic use of internet-related activities across the three time points. Group 2 maintained a moderate level of problematic internet use, and Group 1 maintained the lowest level of problematic internet use (Table 3). Therefore, the first hypothesis was partially supported.

Results of mixed-effect models demonstrated that there were little to no multicollinearity given that the variance inflation factor values were not high (1.01-3.72; Table 4). In addition, homogeneity of variance and linearity for the linear regression models were supported by the residual plots (Fig. 2). Based on the supported assumptions, the mixed-effect models further indicated that scores in problematic internet use (including SABAS, BSMAS, and IGDS9-SF) were significantly associated with the interaction of FCV-19S score and Time in both Groups 1 and 2 but not Group 3 (Table 4). Therefore, post-hoc slope tests were used (Table 5). The results indicated that the participants with a high level of COVID-19-related psychological distress were likely to maintain or increase their problematic internet use (coefficient $[P$-value $]=0.008$ [0.98] for SABAS; 0.119 [0.09] for BSAMS; and 0.149 [0.01] for IGDS9-SF). In contrast, the participants with low level of COVID-19-related psychological distress were likely to decrease their problematic internet use (coefficient $[P$-value $]=-0.493[<0.01]$ for SABAS; -0.119 [0.04] for BSMAS; and -0.101 [0.03] for IGDS9-SF). Therefore, the second hypothesis was supported.

Table 3. Bonferroni post-hoc tests showing change of problematic use of internet-related activities and worry concerning COVID-19 infection

\begin{tabular}{|c|c|c|c|c|}
\hline & Before outbreak (T1) & During outbreak (T2) & During recovery $(\mathrm{T} 3)$ & $\begin{array}{l}\text { Bonferroni } \\
\text { comparison }^{\mathrm{a}}\end{array}$ \\
\hline \multicolumn{5}{|l|}{ Group $1(N=195)$} \\
\hline Worry concerning COVID-19 infection & & $3.86(3.17)$ & $3.01(3.46)$ & $\mathrm{T} 2>\mathrm{T} 3$ \\
\hline FCV-19S & & & $1.83(0.89)$ & \\
\hline SABAS & $1.08(0.26)$ & $1.47(0.68)$ & $1.40(0.72)$ & $\mathrm{T} 2>\mathrm{T} 1, \mathrm{~T} 3>\mathrm{T} 1$ \\
\hline BSMAS & $1.09(0.31)$ & $1.23(0.41)$ & $1.20(0.42)$ & $\mathrm{T} 2>\mathrm{T} 1, \mathrm{~T} 3>\mathrm{T} 1$ \\
\hline IGDS9-SF & $1.02(0.08)$ & $1.13(0.28)$ & $1.16(0.42)$ & $\mathrm{T} 2>\mathrm{T} 1, \mathrm{~T} 3>\mathrm{T} 1$ \\
\hline \multicolumn{5}{|l|}{ Group $2(N=268)$} \\
\hline Worry concerning COVID-19 infection & & $4.50(3.32)$ & $3.87(3.50)$ & $\mathrm{T} 2>\mathrm{T} 3$ \\
\hline FCV-19S & & & $2.23(0.98)$ & \\
\hline SABAS & $1.78(0.63)$ & $1.93(0.94)$ & $1.87(0.93)$ & $\mathrm{T} 2>\mathrm{T} 1$ \\
\hline BSMAS & $1.57(0.51)$ & $1.44(0.65)$ & $1.43(0.62)$ & $\mathrm{T} 1>\mathrm{T} 2, \mathrm{~T} 1>\mathrm{T} 3$ \\
\hline IGDS9-SF & $1.40(0.40)$ & $1.35(0.49)$ & $1.34(0.56)$ & - \\
\hline \multicolumn{5}{|l|}{ Group $3(N=41)$} \\
\hline Worry concerning COVID-19 infection & & $5.18(3.86)$ & $3.61(3.93)$ & - \\
\hline FCV-19S & & & $2.42(1.21)$ & \\
\hline SABAS & $3.81(1.00)$ & $2.50(1.20)$ & $2.35(1.13)$ & $\mathrm{T} 1>\mathrm{T} 2, \mathrm{~T} 1>\mathrm{T} 3$ \\
\hline BSMAS & $2.22(0.81)$ & $1.92(0.90)$ & $1.52(0.61)$ & $\mathrm{T} 1>\mathrm{T} 3, \mathrm{~T} 2>\mathrm{T} 3$ \\
\hline IGDS9-SF & $2.56(0.76)$ & $1.86(0.83)$ & $1.56(0.64)$ & $\mathrm{T} 1>\mathrm{T} 2>\mathrm{T} 3$ \\
\hline \multicolumn{5}{|l|}{ All participants $(N=504)$} \\
\hline Worry concerning COVID-19 infection & & $4.31(3.33)$ & $3.52(3.54)$ & $\mathrm{T} 2>\mathrm{T} 3$ \\
\hline FCV-19S & & & $2.11(1.00)$ & \\
\hline SABAS & $1.68(0.91)$ & $1.80(0.92)$ & $1.72(0.92)$ & $\mathrm{T} 2>\mathrm{T} 1$ \\
\hline BSMAS & $1.44(0.58)$ & $1.40(0.62)$ & $1.35(0.56)$ & $\mathrm{T} 1>\mathrm{T} 3$ \\
\hline \multirow[t]{2}{*}{ IGDS9-SF } & $1.34(0.55)$ & $1.30(0.50)$ & $1.29(0.53)$ & - \\
\hline & \multicolumn{3}{|c|}{ Group comparisons with Bonferroni adjustment $\mathrm{t}^{\mathrm{b}}$} & \\
\hline Worry concerning COVID-19 infection & - & $\mathrm{G} 3>\mathrm{G} 1, \mathrm{G} 2>\mathrm{G} 1$ & $\mathrm{G} 2>\mathrm{G} 1$ & \\
\hline FCV-19S & - & - & $\mathrm{G} 3>\mathrm{G} 1, \mathrm{G} 2>\mathrm{G} 1$ & \\
\hline SABAS & $\mathrm{G} 3>\mathrm{G} 2>\mathrm{G} 1$ & $\mathrm{G} 3>\mathrm{G} 2>\mathrm{G} 1$ & $\mathrm{G} 3>\mathrm{G} 2>\mathrm{G} 1$ & \\
\hline BSMAS & $\mathrm{G} 3>\mathrm{G} 2>\mathrm{G} 1$ & $\mathrm{G} 3>\mathrm{G} 2>\mathrm{G} 1$ & $\mathrm{G} 3>\mathrm{G} 1, \mathrm{G} 2>\mathrm{G} 1$ & \\
\hline IGDS9-SF & $\mathrm{G} 3>\mathrm{G} 2>\mathrm{G} 1$ & $\mathrm{G} 3>\mathrm{G} 2>\mathrm{G} 1$ & G3 > G1, G2 > G1 & \\
\hline
\end{tabular}

SABAS = Smartphone Application Based Addiction Scale; BSMAS = Bergen Social Media Addiction Scale; IGDS9-SF = Nine-item Internet Gaming Disorder Scale-Short Form; FCV-19S = Fear of COVID-19 Scale.

Group 1 = Having the lowest level of problematic internet use; Group 2 = Having the middle level of problematic internet use; Group $3=$ Having the highest level of problematic internet use.

${ }^{\mathrm{a}} \mathrm{T} 1, \mathrm{~T} 2$, and T3 represent before COVID-19 outbreak, during COVID-19 outbreak, and during COVID-19 recovery, respectively.

${ }^{\mathrm{b}} \mathrm{G} 1, \mathrm{G} 2$, and G3 represent Groups 1, 2 and 3 respectively. 
Table 4. Results of mixed-effect models in explaining the association between COVID-19-related distress and problematic internet use

\begin{tabular}{|c|c|c|c|}
\hline & \multicolumn{3}{|c|}{ Coefficient (SE) } \\
\hline & SABAS & BSMAS & IGDS9-SF \\
\hline \multicolumn{4}{|l|}{ Group 1 (VIF from 1.01 to 2.39 ) } \\
\hline Age & $0.002(0.043)$ & $-0.011(0.024)$ & $0.008(0.021)$ \\
\hline Gender (Ref: boys) & $0.002(0.053)$ & $0.004(0.038)$ & $-0.052(0.034)$ \\
\hline Current sick (Ref: no) & $0.138(0.096)$ & $0.194(0.096)^{\star}$ & $0.067(0.037)$ \\
\hline Worry concerning COVID & $0.000(0.016)$ & $0.013(0.011)$ & $-0.002(0.006)$ \\
\hline Time (Ref: Time 1) & $-0.506(0.103)^{\star * \star}$ & $-0.176(0.068)^{\star}$ & $-0.093(0.047)$ \\
\hline Worry concerning COVID ${ }^{\star}$ Time & $-0.046(0.027)$ & $-0.027(0.017)$ & $-0.016(0.012)$ \\
\hline FCV-19S*Time & $0.304(0.086) * *$ & $0.144(0.057)^{\star}$ & $0.128(0.042)^{\star *}$ \\
\hline \multicolumn{4}{|l|}{ Group 2 (VIF from 1.01 to 2.22 ) } \\
\hline Age & $0.024(0.034)$ & $0.004(0.026)$ & $-0.016(0.071)$ \\
\hline Gender (Ref: boys) & $-0.034(0.055)$ & $-0.049(0.041)$ & $-0.027(0.037)$ \\
\hline Current sick (Ref: no) & $-0.160(0.157)$ & $-0.087(0.107)$ & $-0.019(0.071)$ \\
\hline Worry concerning COVID & $0.033(0.018)$ & $0.034(0.014)$ & $0.014(0.009)$ \\
\hline Time (Ref: Time 1) & $-0.199(0.104)$ & $0.139(0.078)$ & $0.049(0.006)$ \\
\hline Worry concerning COVID ${ }^{\star}$ Time & $-0.039(0.027)$ & $-0.034(0.021)$ & $-0.020(0.016)$ \\
\hline FCV-19S*Time & $0.188(0.061)^{\star *}$ & $0.106(0.049)^{*}$ & $0.111(0.048) *$ \\
\hline \multicolumn{4}{|l|}{ Group 3 (VIF from 1.09 to 2.49 ) } \\
\hline Age & $-0.072(0.143)$ & $0.002(0.108)$ & $-0.013(0.105)$ \\
\hline Gender (Ref: boys) & $-0.007(0.2937)$ & $0.004(0.222)$ & $0.350(0.217)$ \\
\hline Current sick (Ref: no) & $-0.421(0.872)$ & $-0.129(0.661)$ & $0.348(0.645)$ \\
\hline Worry concerning COVID & $-0.009(0.052)$ & $0.005(0.040)$ & $0.016(0.039)$ \\
\hline Time (Ref: Time 1) & $1.151(0.265)^{\star * *}$ & $-0.078(0.201)$ & $0.429(0.197)^{*}$ \\
\hline Worry concerning COVID ${ }^{*}$ Time & $-0.009(0.073)$ & $0.027(0.055)$ & $0.007(0.054)$ \\
\hline FCV-19S*Time & $0.384(0.172)^{\star}$ & $0.013(0.130)$ & $0.122(0.127)$ \\
\hline \multicolumn{4}{|c|}{ All participants (VIF from 1.01 to 3.72 ) } \\
\hline Group 1 (Ref: Group 3) & $0.978(0.075)^{\star * *}$ & $0.454(0.064)^{\star * *}$ & $0.614(0.057)^{\star * *}$ \\
\hline Group 2 (Ref: Group 3) & $0.810(0.074)^{\star \star \star}$ & $0.298(0.065)^{\star \star \star}$ & $0.491(0.057)^{\star * \star}$ \\
\hline Age & $0.007(0.025)$ & $0.001(0.018)$ & $-0.011(0.015)$ \\
\hline Gender (Ref: boys) & $-0.012(0.037)$ & $-0.020(0.028)$ & $-0.012(0.026)$ \\
\hline Current sick (Ref: no) & $-0.078(0.114)$ & $0.001(0.079)$ & $0.020(0.049)$ \\
\hline Worry concerning COVID & $0.012(0.013)$ & $0.022(0.009)^{*}$ & $0.007(0.007)$ \\
\hline Time (Ref: Time 1) & $-0.206(0.074)^{\star \star}$ & $0.000(0.053)$ & $0.024(0.042)$ \\
\hline Worry concerning COVID ${ }^{\star}$ Time & $-0.037(0.02)$ & $-0.025(0.014)$ & $-0.016(0.011)$ \\
\hline FCV-19S*Time & $0.289(0.053) * * *$ & $0.119(0.038)^{\star *}$ & $0.126(0.034)^{\star * *}$ \\
\hline
\end{tabular}

SABAS = Smartphone Application Based Addiction Scale; BSMAS = Bergen Social Media Addiction Scale; IGDS9-SF = Nine-item Internet Gaming Disorder Scale-Short Form; FCV-19S = Fear of COVID-19 Scale; VIF = variance inflation factor.

Group 1 = Having the lowest level of problematic internet use; Group 2 = Having the middle level of problematic internet use; Group $3=$ Having the highest level of problematic internet use.

Lastly, the growth mixture model (Fig. 3) showed that the growth of problematic internet use was significant (mean slope coefficient $[P$-value $]=0.20[<0.001]$ for SABAS; 0.21 $[<0.001]$ for BSMAS; and $0.42[<0.001]$ for IGDS9-SF). Moreover, the growth mixture models were all supported by the fit statistics. For SABAS, TLI $=0.931$, CFI $=0.949$, RMSEA $=0.069$, and SRMR $=0.037$. For BSMAS, TLI $=$ $0.990, \mathrm{CFI}=0.995$, RMSEA $=0.016$, and SRMR $=0.026$. For IGDS9-SF, TLI $=0.910, \mathrm{CFI}=0.958, \mathrm{RMSEA}=0.058$, and $\mathrm{SRMR}=0.030$.

\section{DISCUSSION}

Utilizing LCA, participants in the present study were categorized into three groups based on three levels of problematic internet-related use (i.e., smartphone use, social media use, and gaming). Compared to Groups 1 and 2, schoolchildren in Group 3 showed the highest level of problematic use of internet-related activities across the three time points. However, the severity declined significantly from before the COVID-19 outbreak to the COVID-19 outbreak period, and during the COVID-19 recovery period. Conversely, Group 1 demonstrated significantly increased problematic use of internet-related activities during the COVID-19 outbreak which was maintained at the COVID19 recovery period as compared to before the COVID-19 outbreak. Group 2 showed mixed trend with significantly increased PSU as Group 1 but demonstrated decrease in the severity on PSMU across time. Regarding the hypotheses in the present study, both hypotheses were supported (or partially supported by the findings). Groups 3 and 2 had significantly greater worries concerning COVID-19 

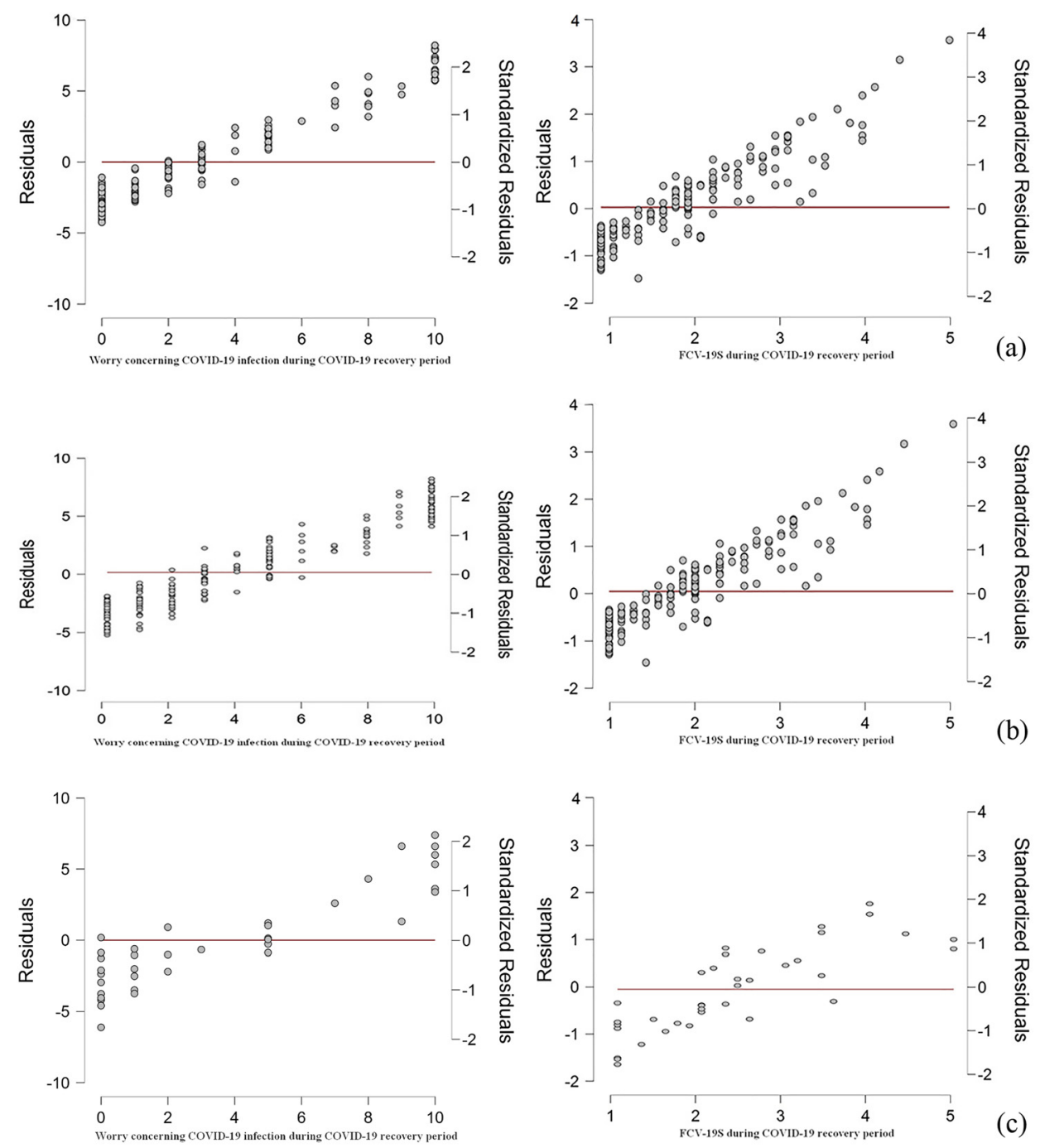

(a) Group 1: Having the lowest level of problematic use

(b) Group 2: Having the middle level of problematic use

(c) Group 3: Having the highest level of problematic use.

FCV-19S=Fear of COVID-19 Scale

Fig. 2. Residual plots for regression models

Table 5. Post-hoc slope tests in examining the difference between significant slopes

\begin{tabular}{|c|c|c|c|}
\hline FCV-19S & SABAS & BSMAS & IGDS \\
\hline \multicolumn{4}{|l|}{ Group 1} \\
\hline High & $-0.204(0.140), P=0.15$ & $-0.034(0.095), P=0.72$ & $0.034(0.063), P=0.59$ \\
\hline Low & $-0.807(0.128), P<0.01^{\star *}$ & $-0.319(0.081), P<0.01^{\star *}$ & $-0.219(0.063), P<0.01^{\star *}$ \\
\hline \multicolumn{4}{|l|}{ Group 2} \\
\hline High & $-0.014(0.126), P=0.91$ & $0.245(0.098), P=0.01^{\star}$ & $0.180(0.089), P=0.04^{\star}$ \\
\hline Low & $-0.384(0.116), P<0.01^{\star \star}$ & $0.034(0.086), P=0.69$ & $-0.081(0.067), P=0.22$ \\
\hline \multicolumn{4}{|l|}{ Group 3} \\
\hline High & $1.093(0.422), P=0.01^{*}$ & $-{ }^{\mathrm{a}}$ & $-{ }^{\mathrm{a}}$ \\
\hline Low & $1.208(0.289), P<0.01^{\star *}$ & $-{ }^{\mathrm{a}}$ & $-{ }^{\mathrm{a}}$ \\
\hline \multicolumn{4}{|c|}{ All participants } \\
\hline High & $0.008(0.092), P=0.98$ & $0.119(0.071), P=0.09$ & $0.149(0.059), P=0.01^{\star}$ \\
\hline Low & $-0.493(0.083), P<0.01^{\star \star}$ & $-0.119(0.063), P=0.04^{\star}$ & $-0.101(0.048), P=0.03^{\star}$ \\
\hline
\end{tabular}

${ }^{a}$ Post-hoc slope tests were not performed due to the nonsignificant interaction effects (Please see Table 4). 
(a) SABAS; (b) BSMAS; (c) IGDS9-SF.

\begin{tabular}{|l|l|c|c|c|c|c|}
\hline & & $\chi^{2}(d f)$ & TLI & CFI & RMSEA & SRMR \\
\hline \multirow{2}{*}{$\begin{array}{l}\text { Growth } \\
\text { mixture } \\
\text { model }\end{array}$} & SABAS $^{\mathrm{a}}$ & $23.68(7)$ & 0.931 & 0.949 & 0.069 & 0.037 \\
\cline { 2 - 7 } & BSMAS $^{\mathrm{b}}$ & $7.92(7)$ & 0.990 & 0.995 & 0.016 & 0.026 \\
\cline { 2 - 7 } & IGDS9-SF $^{\mathrm{c}}$ & $18.75(7)$ & 0.910 & 0.958 & 0.058 & 0.030 \\
\hline
\end{tabular}

$d f=$ degree of freedom; TLI=Tucker-Lewis Index; CFI=Comparative Fit Index; RMSEA=root mean square error of approximation; $\mathrm{SRMR}=$ standardized root mean square residual

${ }^{\mathrm{a}}$ Mean of intercept $=1.55, \mathrm{t}=23.39, \mathrm{p}<0.001$; Mean of slope $=0.20, \mathrm{t}=5.15, \mathrm{p}<0.001$

${ }^{\mathrm{b}}$ Mean of intercept $=1.83, \mathrm{t}=23.84, \mathrm{p}<0.001$; Mean of slope $=0.21, \mathrm{t}=4.59, \mathrm{p}<0.001$

${ }^{\mathrm{c}}$ Mean of intercept $=0.91, \mathrm{t}=18.16, \mathrm{p}<0.001$; Mean of slope $=0.42, \mathrm{t}=13.15, \mathrm{p}<0.001$
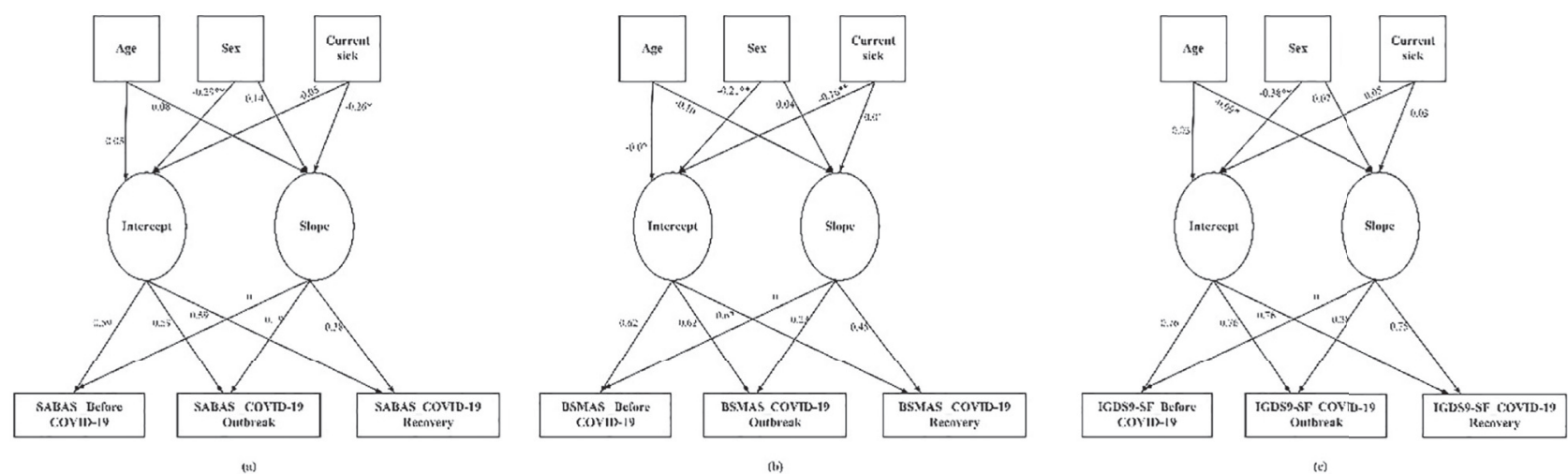

Fig. 3. Growth mixture model results showing the trajectory of problematic internet use

infection during outbreak period and more fear of COVID19 during COVID-19 recovery period than Group 1 (Table 3). Furthermore, the fear of COVID-19 was associated with the severity of problematic internet use in Group 1 and 2. A similar result only presented on PSU in Group 3 (Table 4).

During the outbreak of COVID-19, schoolchildren (especially those with low or moderate level of problematic internet-related activities) may have used the internet including social media to search for pandemic-related information as well as seeking social support from friends when school was suspended (Nagata, Abdel Magid, \& Pettee Gabriel, 2020). This could have led to the increased time using the internet and (for some) problematic internet use (Sun et al., 2020). Moreover, schoolchildren adopted distance (online) learning at home to help control the spread of the virus, and this additional internet exposure may have resulted in problematic internet-related uses. In the present study, participants in Group 3 showed the highest level of problematic internet use but this decreased during the COVID-19 outbreak period. It could be that their desire of using the internet may have decreased after prolonged exposure to internet for the needs of distance learning on top of the existing problematic behaviors including excessive internet using time (Chen, Chen, Pakpour, Griffiths, \& Lin, 2020; Chen, Chen, O’Brien, Latner, \& Lin, 2021). Also, considering that Group 3 contained higher proportion of (older) Grade 6 participants than Groups 1 and 2, the studying load might be higher among Group 3 participants than the other two groups. The heavier studying load may have resulted in a longer online learning time (i.e., a prolonged screen time), which then turned out to be a protective factor in inhibiting problematic internet use. During the COVID-19 recovery period, the resumption of school life and face-to-face peer relationships may have also reduced problematic internet use (e.g., through increased social support) and enhanced the satisfactory of quality of life, which may have led to further palliative effect in relation to problematic internet use among Group 3 participants ( $\mathrm{Pal}$ Singh Balhara \& Singh, 2019). These findings may also explain the results regarding significantly higher levels of worry of COVID-19 among both Groups 1 and 2 during the outbreak period. However, there were fewer such impacts in Group 3.

Participants in Groups 1 and 2 demonstrated increased problematic use of internet during the COVID-19 outbreak period. Internet-related activities may have been a major channel for schoolchildren to search for COVID-19-related information, seeking social support and/or serving as coping strategies in responding to the radical change of lifestyle during the school suspension period (Chen, Chen, et al., 2020; Chen, Chen, O’Brien, et al., 2021). Therefore, a vicious cycle may have been generated and subsequently worsened their problematic internet-related behaviors (Sun et al., 2020). Problematic use of internet decreased during the COVID-19 recovery period in Group 2. This may have 
been the relaxation of the 'stay-at-home' restrictions, which may have led to decreased desire and need for psychological support through internet (Wang \& Wang, 2013). Meanwhile, a similar effect during the COVID-19 recovery period might be less dominant among participants in Group 1 , who had less concerns related to problematic internetrelated activities.

Overall, Groups 2 and 3 had higher level of worry and fear of being infected by COVID-19 compared to Groups 1. This leads to the speculation that schoolchildren with more severe problematic use of internet-related behaviors may be more exposed to COVID-19 relevant information. This may then result in exaggerated distress toward COVID-19 (Ahmad \& Murad, 2020). The present results further indicated that the fear of COVID-19 maintained or increased among those with more problematic internet use while less fear of COVID-19 was accompanied by decreased problematic internet use. This can be interpreted by the fact that the association between the severity of problematic internet use and COVID-19 was related to psychological distress. Moreover, changes in problematic internet use were predictors of fear of COVID-19 during the recovery period. This means that schoolchildren who had decreased problematic internet use as assessed using BSMAS and IGDS9-SF in Groups 1 and 2 and SABAS in all three groups had less fear of COVID-19. In other words, inappropriate use of internet during the pandemic may cause psychological distress among schoolchildren, which also supports previous speculation (Seyed Hashemi et al., 2020) regarding the relationship between problematic internet use and psychological distress toward COVID-19.

Increased time using the internet was unavoidable during the outbreak of COVID-19 when city lockdown and the school suspension were implemented. Taking all the present findings into consideration, the purpose of internet use and information acquired through online activities may have initiated the origins of problematic internet use on top of increased internet use irrespective of the usual online habits among schoolchildren. Therefore, adopting strategies to monitor internet uses supplemented with other support, such as recognition of social needs and appropriate education on perceiving pandemic-related information, may give rise to more efficacious approaches in facilitating good mental health among children. In this case, the recovery process of overcoming problematic internet use and psychological distress as consequences of pandemic outbreak, may also be faster. Considering that (at the time of writing) many countries are still implementing school suspensions to minimize the spread of COVID-19, results from the present study may provide valuable information as a reference to consider mitigation plans to protect schoolchildren from mental health threats due to the pandemic.

There are some limitations to the present study. First, the results may not be generalized to other counties with different policies for COVID-19 infection control (e.g., school suspensions) and culture. For example, parents/ caregivers' supervision methods may lead to different home learning outcomes or internet using habit (Karaer \&
Akdemir, 2019), especially when online distance learning is implemented during the pandemic. Second, the data of fear of being infected by COVID-19 was only reported during the recovery period (because no scale had been developed and validated until March 2020), and therefore it could not reflect the changing direction since the outbreak of COVID19. This could have provided important information to guide the development and monitoring plan on internet use among schoolchildren during the COVID-19 pandemic outbreak. Third, the survey did not include any kind of counterbalanced design nor an attentional check item. Therefore, the accuracy of the participants' answers might have been impacted. However, given that all the used measures had satisfactory internal consistency in the present study, the lack of a counterbalanced design or an attention check item is not thought to have seriously biased the findings. Moreover, there was no direct information regarding the purposes and associated time distribution when using internet and social media. Therefore, the relationship between the exposure to COVID-19 information, problematic use of internet-related activities, and COVID-19 related distress could not be fully confirmed directly. Finally, the generalizability of the findings to non-Chinese schoolchildren is unknown because many factors in the present study may be different in other countries (e.g., internet use habit, parental coaching methods, duration and severity of COVID-19 outbreak, and government policies). However, principles of the proposed implications are generally universal, which are especially valuable when there is no localized evidence available. In addition, the data points in the present study included the recovery period, which gives an insight into potential needs to maintain good mental health after the pandemic is over. However, the results should be interpreted with caution before other countries implement supportive and mitigating plans for psychological and behavioral concerns among schoolchildren.

\section{CONCLUSION}

Schoolchildren with varied levels of problematic use of internet (including that via smartphones) may demonstrate different changing trends of problematic behaviors during COVID-19 outbreak and recovery periods. Nevertheless, increased problematic internet-related use was predictive of more worry and fear of being infected by COVID-19 irrespective of the severity of different types of problematic internet use. Therefore, appropriate monitoring plans concerning internet using habits among schoolchildren is recommended to prevent or inhibit their psychological distress.

Funding source: This research was supported in part by Higher Education Sprout Project, Ministry of Education to the Headquarters of University Advancement at National Cheng Kung University (NCKU) and in part by a research grant from the Taipei Municipal Wanfang Hospital CrossInstitutions Fund (110-swf-01). 
Authors' contribution: C-YC, I-HC, S-MW, and C-YL created and organized the study and collected the data. DWA, C-hL, Y-PC, Y-JK, I-HC, and C-YL analyzed the data; C-YC, I-HC, DKA, S-MW, and C-YL wrote the first $\mathrm{draft}$ and analyzed data. AHP provided the directions of data analysis. C-YC, I-HC, DKA, S-MW, and MDG interpreted the data results. MDG supervised the entire study and was responsible for all final editing. C-YC, S-MW, Y-PC, Y-CK, and $\mathrm{C}-\mathrm{YL}$ responded to the reviewers' comments and revised the manuscript. All the authors critically reviewed the manuscript and provided constructive comments.

Conflicts of interest: The authors have no conflicts of interest relevant to this article to disclose.

\section{REFERENCES}

Ahmad, A. R., \& Murad, H. R. (2020). The impact of social media on panic during the COVID-19 pandemic in Iraqi Kurdistan: Online questionnaire study. Journal of Medical Internet Research, 22(5), e19556. https://doi.org/10.2196/19556.

Ahorsu, D. K., Imani, V., Lin, C.-Y., Timpka, T., Broström, A., Updegraff, J. A., ... Pakpour, A. H. (2020). Associations between fear of COVID-19, mental health, and preventive behaviours across pregnant women and husbands: An actorpartner interdependence modelling. International Journal of Mental Health and Addiction. Advance online publication. https://doi.org/10.1007/s11469-020-00340-X.

Ahorsu, D. K., Lin, C.-Y., Imani, V., Saffari, M., Griffiths, M. D., \& Pakpour, A. H. (2020). The fear of COVID-19 scale: Development and initial validation. International Journal of Mental Health and Addiction. Advance online publication. https://doi. org/10.1007/s11469-020-00270-8.

Ahorsu, D. K., Lin, C.-Y., \& Pakpour, A. H. (2020). The association between health status and insomnia, mental health, and preventive behaviors: The mediating role of fear of COVID-19. Gerontology and Geriatric Medicine, 6, 2333721420966081. https://doi.org/10.1177/2333721420966081.

Altundağ, Y., Yandi, A., \& Ünal, A. (2019). Adaptation of application-based smartphone addiction scale to Turkish cultures. Sakarya University Journal of Education, 9(2), 261-281. https:// doi.org/10.19126/suje.516365.

Alyami, M., Henning, M., Krägeloh, C. U., \& Alyami, H. (2020). Psychometric evaluation of the Arabic version of the fear of COVID-19 scale. International Journal of Mental Health and Addiction. Advance online publication. Advance online publication. https://doi.org/10.1007/s11469-020-00316-x.

American Psychiatric Association (2013). Diagnostic and statistical manual of mental disorders (5th ed.). Arlington, VA: American Psychiatric Association.

Andreassen, C. S., Billieux, J., Griffiths, M. D., Kuss, D. J., Demetrovics, Z., Mazzoni, E., \& Pallesen, S. (2016). The relationship between addictive use of social media and video games and symptoms of psychiatric disorders: A large-scale cross-sectional study. Psychology of Addictive Behaviors, 30(2), 252-262. https://doi.org/10.1037/adb0000160.
Arıcak, O. T., Dinç, M., Yay, M., \& Griffiths, M. D. (2019). Adapting the short form of the internet gaming disorder scale into Turkish: Validity and reliability. Addicta: The Turkish Journal on Addictions, 5, 629-635. https://doi.org/10.15805/ addicta.2019.6.1.0027.

Asmundson, G. J. G., \& Taylor, S. (2020). Coronaphobia: Fear and the 2019-nCoV outbreak. Journal of Anxiety Disorders, 70, 102196. http://dx.doi.org/10.1016/j.janxdis.2020.102196.

Bányai, F., Zsila, Á., Király, O., Maraz, A., Elekes, Z., Griffiths, M. D., ... Demetrovics, Z. (2017). Problematic social media use: Results from a large-scale nationally representative adolescent sample. Plos One, 12(1), e0169839. https://doi.org/10.1371/ journal.pone.0169839.

Beranuy, M., Machimbarrena, J. M., Vega-Osés, M. A., Carbonell, X., Griffiths, M. D., Pontes, H. M., \& González-Cabrera, J. (2020). Spanish validation of the Internet Gaming Disorder Scale-Short Form (IGDS9-SF): Prevalence and relationship with online gambling and quality of life. International Journal of Environmental Research and Public Health, 17, 1562. https:// doi.org/10.3390/ijerph17051562.

Bitan, D. T., Grossman-Giron, A., Bloch, Y., Mayer, Y., Shiffman, N., \& Mendlovic, S., (2020). Fear of COVID-19 scale: Psychometric characteristics, reliability and validity in the Israeli population. Psychiatry Research, 289, 113100. https://doi.org/ 10.1016/j.psychres.2020.113100.

Cachón-Zagalaz, J., Sánchez-Zafra, M., Sanabrias-Moreno, D., González-Valero, G., Lara-Sánchez, A. J., \& Zagalaz-Sánchez, M. L. (2020). Systematic Review of the literature about the effects of the COVID-19 pandemic on the lives of school children. Frontiers in Psychology, 11, 569348. https://doi.org/10. 3389/fpsyg.2020.569348.

Chang, Y.-H., Chang, K.-C., Hou, W.-L., Lin, C.-Y., \& Griffiths, M. D. (2020). Internet gaming as a coping method among schizophrenic patients facing psychological distress. Journal of Behavioral Addictions, 9(4), 1022-1031. https://doi.org/10. 1556/2006.2020.00081.

Chang, K.-C., Hou, W.-L., Pakpour, A. H., Lin, C.-Y., \& Griffiths, M. D. (2020). Psychometric testing of three COVID-19-related scales among people with mental illness. Advance online publication. International Journal of Mental Health and Addiction. https://doi.org/10.1007/s11469-02000361-6.

Chen, I.-H., Ahorsu, D. K., Pakpour, A. H., Griffiths, M. D., Lin, C.Y., \& Chen, C.-Y. (2020). Psychometric properties of three simplified Chinese online-related addictive behavior instruments among mainland Chinese primary school students. Frontiers in Psychiatry, 11, 875. https://doi.org/10.3389/fpsyt. 2020.00875.

Chen, C.-Y., Chen, I.-H., Hou, W.-L., Potenza, M. N., O’Brien, K. S., Lin, C.-Y., \& Latner, J. D. (2021). The relationship between children's problematic internet-related behaviors and psychological distress during the onset of the COVID-19 pandemic: A longitudinal study. Journal of Addiction Medicine. Advance online publication. https://doi.org/10.1097/ADM. 0000000000000845.

Chen, C.-Y., Chen, I.-H., O’Brien, K. S., Latner, J. D., \& Lin, C.-Y. (2021). Psychological distress and internet-related behaviors between schoolchildren with and without overweight during 
the COVID-19 outbreak. International Journal of Obesity, 45(3), 677-686. https://doi.org/10.1038/s41366-021-00741-5.

Chen, I.-H., Chen, C.-Y., Pakpour, A. H., Griffiths, M. D., \& Lin, C.-Y. (2020). Internet-related behaviors and psychological distress among schoolchildren during COVID-19 school suspension. Journal of the American Academy of Child and Adolescent Psychiatry, 159(10), 1099-1102. https://doi.org/10. 1016/j.jaac.2020.06.007.

Chen, C.-Y., Chen, I.-H., Pakpour, A. H., Lin, C.-Y., \& Griffiths, M. D. (2021). Internet-related behaviors and psychological distress among schoolchildren during the COVID-19 school hiatus. Cyberpsychology, Behavior, and Social Networking. Advance online publication. https://doi.org/10.1089/cyber.2020. 0497.

Chen, I.-H., Pakpour, A. H., Leung, H., Potenza, M. N., Su, J.-A., Lin, C.-Y., \& Griffiths, M. D. (2020). Comparing generalized and specific problematic smartphone/internet use: Longitudinal relationships between smartphone application-based addiction and social media addiction and psychological distress. Journal of Behavioral Addictions, 9(2), 410-419. https://doi.org/10. 1556/2006.2020.00023.

Chen, I.-H., Strong, C., Lin, Y.-C., Tsai, M.-C., Leung, H., Lin, C.Y., ... Griffiths, M. D. (2020). Time invariance of three ultrabrief internet-related instruments: Smartphone applicationbased addiction scale (SABAS), Bergen social media addiction scale (BSMAS), and the nine-item internet gaming disorder scale- short form (IGDS-SF9) (study Part B). Addictive Behaviors, 101, 105960. https://doi.org/10.1016/j.addbeh.2019. 04.018.

Csibi, S., Demetrovics, Z., \& Szabo, A. (2016). Hungarian adaptation and psychometric characteristics of brief addiction to smartphone scale (BASS) [in Hungarian]. Psychiatria Hungarica, 31(1), 71-77.

Csibi, S., Griffiths, M. D., Cook, B., Demetrovics, Z., \& Szabo, A. (2018). The psychometric properties of the smartphone application-based addiction scale (SABAS). International Journal of Mental Health and Addiction, 16(2), 393-403. https://doi.org/ 10.1007/s11469-017-9787-2.

Di Blasi, M., Gullo, S., Mancinelli, E., Freda, M. F., Esposito, G., Gelo, O., ... Lo Coco, G. (2021). Psychological distress associated with the COVID-19 lockdown: A two-wave network analysis. Journal of Affective Disorders, 284, 18-26. https://doi. org/10.1016/j.jad.2021.02.016.

Dong, H., Yang, F., Lu, X., \& Hao, W. (2020). Internet addiction and related psychological factors among children and adolescents in China during the Coronavirus Disease 2019 (COVID19) epidemic. Frontiers in Psychiatry, 11, 00751 http://dx.doi. org/10.3389/fpsyt.2020.00751.

Fazeli, S., Mohammadi Zeidi, I., Lin, C.-Y., Namdar, P., Griffiths, M. D., Ahorsu, D. K., \& Pakpour, A. H. (2020). Depression, anxiety, and stress mediate the associations between internet gaming disorder, insomnia, and quality of life during the COVID-19 outbreak. Addictive Behaviors Reports, 12, 100307. https://doi.org/10.1016/j.abrep.2020.100307.

Fisher, G. G., Matthews, R. A., \& Gibbons, A. M. (2016). Developing and investigating the use of single-item measures in organizational research. Journal of Occupational Health Psychology, 21(1), 3-23. https://doi.org/10.1037/a0039139.
Gökler, M. E., \& Bulut, Y. E. (2019). Validity and reliability of the Turkish version of the smart phone application based addiction scale. Journal of Cognitive-Behavioral Psychotherapy and Research, 8(2), 100-106. https://doi.org/10.5455/bcp.20140710040824.

Griffiths, M. D. (2000). Internet addiction - Time to be taken seriously? Addiction Research, 8(5), 413-418. https://doi.org/10. 3109/16066350009005587.

Griffiths, M. D. (2005). A 'components' model of addiction within a biopsychosocial framework. Journal of Substance Use, 10, 191197. https://doi.org/10.1080/14659890500114359.

Hurwitz, L. B., \& Schmitt, K. L. (2020). Can children benefit from early internet exposure? Short- and long-term links between internet use, digital skill, and academic performance. Computers \& Education, 146, 103750. https://doi.org/10.1016/j. compedu.2019.103750.

Jeon, S., Lee, J., Anthony, J. C., \& Chung, H. (2017). Latent class analysis for multiple discrete latent variables: A study on the association between violent behavior drug-using behaviors. Structural Equation Modeling, 24(6), 911-925. https://doi.org/ 10.1080/10705511.2017.1340844.

Karaer, Y., \& Akdemir, D. (2019). Parenting styles, perceived social support and emotion regulation in adolescents with internet addiction. Comprehensive Psychiatry, 92, 22-27. https://doi.org/ 10.1016/j.comppsych.2019.03.003.

Kardefelt-Winther, D. (2014). A conceptual and methodological critique of internet addiction research: Towards a model of compensatory internet use. Computers in Human Behavior, 31, 351-354. https://doi.org/10.1016/j.chb.2013.10.059.

Leung, H., Pakpour, A. H., Strong, C., Lin, Y.-C., Tsai, M.-C., Griffiths, M. D., ... Chen, I.-H. (2020). Measurement invariance across young adults from Hong Kong and Taiwan among three internet-related addiction scales: Bergen social media addiction scale (BSMAS), smartphone application-based addiction scale (SABAS), and internet gaming disorder scaleshort form (IGDS-SF9) (study part A). Addictive Behaviors, 101, 105969. https://doi.org/10.1016/j.addbeh.2019.04.027.

Lin, C.-Y., Broström, A., Nilsen, P., Griffiths, M. D., \& Pakpour, A. H. (2017). Psychometric validation of the Persian Bergen social media addiction scale using classic test theory and Rasch models. Journal of Behavioral Addictions, 6(4), 620-629. https:// doi.org/10.1556/2006.6.2017.071.

Lin, M.-W., \& Cheng, Y. (2020). Policy actions to alleviate psychosocial impacts of COVID-19 pandemic: Experiences from Taiwan [Letter to Editor]. Social Health and Behavior, 3(2), 72-73. https://doi.org/10.4103/shb.Shb_18_20.

Lin, C. Y., Hou, W. L., Mamun, M. A., Aparecido da Silva, J., Broche-Pérez, Y., Ullah, I., .. Pakpour, A. H. (2021). Fear of COVID-19 Scale (FCV-19S) across countries: Measurement invariance issues. Nursing Open, 10.1002/nop2.855. Advance online publication. https://doi.org/10.1002/nop2.855.

Lin, C.-Y., Imani, V., Broström, A., Nilsen, P., Fung, X. C. C., Griffiths, M. D., \& Pakpour, A. H. (2019). Smartphone application-based addiction among Iranian adolescents: A psychometric study. International Journal of Mental Health and Addiction, 17(4), 765-780. https://doi.org/10.1007/s11469-0180026-2.

Monacis, L., de Palo, V., Griffiths, M. D., \& Sinatra, M. (2016). Validation of the internet gaming disorder scale-short form 
(IGDS9-SF) in an Italian-speaking sample. Journal of Behavioral Addictions, 5(4), 683-690. https://doi.org/10.1556/2006.5. 2016.083.

Monacis, L., de Palo, V., Griffiths, M. D., \& Sinatra, M. (2017). Social networking addiction, attachment style, and validation of the Italian version of the Bergen Social Media Addiction Scale. Journal of Behavioral Addictions, 6(2),178-186. https://doi.org/ 10.1556/2006.6.2017.023.

Montag, C., Wegmann, E., Sariyska, R., Demetrovics, Z., \& Brand, M. (2020). How to overcome taxonomical problems in the study of Internet use disorders and what to do with "smartphone addiction"? Journal of Behavioral Addictions, 9(3), 908914. https://doi.org/10.1556/2006.8.2019.59.

Nagata, J. M., Abdel Magid, H. S., \& Pettee Gabriel, K. (2020). Screen time for children and adolescents during the coronavirus disease 2019 pandemic. Obesity, 28(9), 1582-1583. https:// doi.org/10.1002/oby.22917.

Pakpour, A. H., Griffiths, M. D., Chang, K.-C., Chen, Y.-P., Kuo, Y.-J., \& Lin, C.-Y. (2020). Assessing the fear of COVID-19 among different populations: A response to Ransing et al. Brain, Behavior, and Immunity. https://doi.org/10.1016/j.bbi.2020.06.006.

Pakpour, A. H., Griffiths, M. D., \& Lin, C. Y. (2020). Assessing the psychological response to the COVID-19: A response to Bitan et al. "Fear of COVID-19 scale: Psychometric characteristics, reliability and validity in the Israeli population". Psychiatry Research, 290, 113127. https://doi.org/10.1016/j.psychres.2020. 113127.

Pal Singh Balhara, Y., \& Singh, S. (2019). Online course on basics of management of behavioral addictions involving use of internet: Observations from the first batch of participants. Asian Journal of Psychiatry, 44, 1-3. https://doi.org/10.1016/j.ajp.2019.07.013.

Pang, N., Kamu, A., Hambali, N., Mun, H. C., Kassim, M. A., Mohamed, N. H., .. J Jeffree, M. S. (2020). Malay version of the fear of COVID-19 scale: Validity and reliability. International Journal of Mental Health and Addiction. Advance online publication. https://doi.org/10.1007/s11469-020-00355-4.

Pontes, H. M., \& Griffiths, M. D. (2015). Measuring DSM-5 internet gaming disorder: Development and validation of a short psychometric scale. Computers in Human Behavior, 45, 137-143. https://doi.org/10.1016/j.chb.2014.12.006.

Pontes, H. M., Macur, M., \& Griffiths, M. D. (2016). Internet gaming disorder among Slovenian primary schoolchildren: Findings from a nationally representative sample of adolescents. Journal of Behavioral Addictions, 5(2), 304-310. https:// doi.org/10.1556/2006.5.2016.042.

Pontes, H. M., Stavropoulos, V., \& Griffiths, M. D. (2017). Measurement invariance of the internet gaming disorder scaleshort-form (IGDS9-SF) between the United States of America, India and the United Kingdom. Psychiatry Research, 257, 472478. https://doi.org/10.1016/j.psychres.2017.08.013.

Rogers, R. W. A. (1975). Protection Motivation Theory of fear appeals and attitude change. Journal of Psychology, 91(1), 93114, https://doi.org/10.1080/00223980.1975.9915803.

Ruiz-Ariza, A., Casuso, R. A., Suarez-Manzano, S., \& MartínezLópez, E. (2018). Effect of augmented reality game Pokémon GO on cognitive performance and emotional intelligence in adolescent young. Computers \& Education, 116, 49-63. https:// doi.org/10.1016/j.compedu.2017.09.002.
Sakib, N., Bhuiyan, A., Hossain, S., Al Mamun, F., Hosen, I., Abdullah, A. H., ... Mamun, M. A. (2020). Psychometric validation of the Bangla fear of COVID-19 scale: Confirmatory factor analysis and Rasch analysis. International Journal of Mental Health and Addiction. Advance online publication. https://doi.org/10.1007/s11469-020-00289-x.

Satici, B., Gocet-Tekin, E., Deniz, M. E., \& Satici, S. A. (2020). Adaptation of the Fear of COVID-19 Scale: Its association with psychological distress and life satisfaction in Turkey. International Journal of Mental Health and Addiction. Advance online publication. https://doi.org/10.1007/s11469-020-00294-0.

Seyed Hashemi, S. G., Hosseinnezhad, S., Dini, S., Griffiths, M. D., Lin, C. Y., \& Pakpour, A. H. (2020). The mediating effect of the cyberchondria and anxiety sensitivity in the association between problematic internet use, metacognition beliefs, and fear of COVID-19 among Iranian online population. Heliyon, 6(10), e05135. https://doi.org/10.1016/j.heliyon.2020. e05135.

Shaw, M., \& Black, D. W. (2008). Internet addiction: Definition, assessment, epidemiology and clinical management. CNS Drugs, 22(5), 353-365. https://doi.org/10.2165/00023210200822050-00001.

Siste, K., Hanafi, E., Sen, L. T., Christian, H., Adrian, Siswidiani, L. P., ... Suwartono, C. (2020). The impact of physical distancing and associated factors towards internet addiction among adults in Indonesia during COVID-19 pandemic: A nationwide webbased study. Frontiers in Psychiatry, 11, 580977. https://doi.org/ 10.3389/fpsyt.2020.580977.

Sojević, M., Pećanac, D., \& Latas, M. (2018). Connection of depression, anxiety and impulsivity with the way of using modern mobile phones among students. Medicinski Podmladak, 69(4), 27-34. https://doi.org/10.5937/mp69-17929.

Soraci, P., Ferrari, A., Abbiati, F. A., Del Fante, E., De Pace, R., Urso, A., \& Griffiths, M. D. (2020). Validation and psychometric evaluation of the Italian version of the Fear of COVID19 Scale. International Journal of Mental Health and Addiction. Advance online publication. https://doi.org/10.1007/s11469020-00277-1.

Soraci, P., Ferrari, A., Urso, A., \& Griffiths, M. D. (2020). Psychometric properties of the Italian version of the smartphone application-based addiction scale (SABAS). International Journal of Mental Health and Addiction. Advance online publication. https://doi.org/10.1007/s11469-020-00222-2.

Sun, Y., Li, Y., Bao, Y., Meng, S., Sun, Y., Schumann, G., ... Shi, J. (2020). Brief report: Increased addictive internet and substance use behavior during the COVID-19 pandemic in China. American Journal on Addictions, 29(4), 268-270. https://doi. org/10.1111/ajad.13066.

T'ng, S. T., \& Pau, K. (2020). Validation of a translated Internet Gaming Disorder Scale (short form) and measurement invariance across sex groups in Malaysian samples. Current Psychology. Advance online publication. https://doi.org/10.1007/ s12144-020-00668-6.

Tsipropoulou, V., Nikopoulou, V. A., Holeva, V., Nasika, Z., Diakogiannis, I., Sakka, S., ... Parlapani, E. (2020). Psychometric properties of the Greek version of FCV-19S. International Journal of Mental Health and Addiction. Advance online publication. https://doi.org/10.1007/s11469-020-00319-8. 
Wang, E. S.-T., \& Wang, M. C.-H. (2013). Social support and social interaction ties on internet addiction: Integrating online and offline contexts. Cyberpsychology, Behavior, and Social Networking, 16(11), 843-849. https://doi.org/10.1089/cyber.2012.0557.

Weinstein, A., Feder, L. C., Rosenberg, K. P., \& Dannon, P. (2014). Internet addiction: Overview and controversies. In K. P. Rosenberg, \& L. C. Feder (Eds.), Behavioral addictions: Criteria, evidence, and treatment (pp. 99-117). New York: Academic Press.

Wu, T.-Y., Lin, C.-Y., Årestedt, K., Griffiths, M. D., Broström, A., \& Pakpour, A. H. (2017). Psychometric validation of the
Persian nine-item Internet Gaming Disorder Scale-Short Form: Does gender and hours spent online gaming affect the interpretations of item descriptions? Journal of Behavioral Addictions, 6(2), 256-263. https://doi.org/10.1556/2006.6.2017. 025.

Yam, C. W., Pakpour, A. H., Griffiths, M. D., Yau, W. Y., Lo, C. M., Ng, J., ... Leung, H. (2019). Psychometric testing of three Chinese online-related addictive behavior instruments among Hong Kong university students. Psychiatric Quarterly, 90(1), 117-128. https://doi.org/10.1007/s11126-018-9610-7. 